\title{
AUTOIMMUNE INFLAMMATORY MYOPATHY AFTER CHIKUNGUNYA INFECTION
}

Raiza Cansian Tuão ${ }^{1, \star}$, Paula dos Santos Athayde ${ }^{1}$, Ketty Lysie Libardi Lira Machado¹, Estephania Pignaton Naseri¹, Bárbara Ferraço Dalmaso ${ }^{1}$, Gustavo Pinto de Oliveira Gomes ${ }^{1}$, Débora Marques Veghini ${ }^{1}$, Ruben Horst Duque ${ }^{1}$, Lídia Balarini da Silva ${ }^{1}$, Ana Paula Espíndula Gianordoli1, Bárbara Petronetto Fafá ${ }^{1}$, Érica Vieira Serrano ${ }^{1}$, Luiza Correa Rodrigues Dalpiero ${ }^{1}$, Weider Andrade Tomé ${ }^{1}$, Luiza Vallory Alochio ${ }^{1}$, Pedro Hugo Silva Ramos ${ }^{1}$, Filipe Faé ${ }^{1}$, Bethânia Silva Meireles ${ }^{1}$, Pedro Gabriel Coffler Zorzal $^{1}$, Pedro Zamprogno Caser ${ }^{1}$, Rafael Burgomeister Lourenço1 ${ }^{1}$, Valéria Valim ${ }^{1}$

1. Hospital Universitário Cassiano Antonio Moraes, Vitória (ES), Brazil.

*Corresponding author: raizatuao@hotmail.com

\section{BACKGROUND}

Chikungunya is an arbovirosis that has become endemic in Brazil. Studies suggest that viral infections can be triggers for idiopathic inflammatory myopathies, as well as for other autoimmune diseases. On the other hand, inflammatory myositis in association with chikungunya is rare and always in the acute phase of the disease. In this context, the aim of this report is to demonstrate the association between Chikungunya and immune-mediated inflammatory myopathy, an association still rare in the literature.

\section{CASE REPORT}

A 38-year-old female patient presented with acute diarrhea, fever, myalgia and polyarthritis, in March 2021, and was diagnosed with Chikungunya, confirmed by a positive ELISA IgM test. After two months, she presented with proximal weakness of lower and upper limb muscles, dysphagia, dysphonia and dyspnea, and was admitted to our service on June 2021. Upon physical examination, she presented with decreased proximal strength in the lower limbs muscles (grade 2) and in the upper limbs muscles (grade 3). The exams showed elevated creatine phosphokinase (CPK $25150 \mathrm{U} / \mathrm{L}$ ) and positive anti-Jo-1 antibody. Electroneuromyography confirmed a pattern of myopathy in the four limbs, with proximal predominance, and magnetic resonance imaging of the thighs showed diffuse edema of the muscles, suggesting an inflammatory process. Chest computerized tomography scan showed groundglass opacities in bases up to the middle third of the lungs, consistent with nonspecific interstitial pneumopathy (NSIP). Infectious etiologies (viral such as hepatitis and COVID-19), metabolic disorders, drugs and neoplasms were excluded. The diagnosis of immune-mediated inflammatory myopathy, antisynthetase syndrome, post Chikungunya infection, was established and pulse therapy with methylprednisolone and human immunoglobulin was initiated. Patient had a satisfactory clinical response in addition to a gradual decrease in CPK (5126 U/L). She continues to be followed as an outpatient, with monthly use of immunoglobulin and cyclophosphamide.

\section{CONCLUSION}

To our knowledge this is the first case of post-chikungunya infection antisynthetase syndrome characterized by quadriplegia, interstitial lung disease and positive anti-Jo-1. The chikungunya infection was two months before it was likely a trigger for the development of autoimmunity. Therefore, further research is suggested to consolidate the correlation between chikungunya infection and autoimmune inflammatory myopathy.

\section{KEYWORDS}

Virus diseases, Myositis, Muscular diseases. 